\title{
TERRITÓRIO, POLÍTICA E INFRAESTRUTURAS: A INFLUÊNCIA DO GOVERNO FEDERAL NA POLÍTICA URBANA DOS MUNICÍPIOS BRASILEIROS
}

\section{Territory, politics and infrastructures: the influence of the federal government in urban policy of the Brazilian municipalities}

\author{
Fabrício Gallo \\ Professor Asissistente Doutor \\ Universidade Estadual Paulista (UNESP), Rio Claro, São Paulo, Brasil \\ fgallo@rc.unesp.br
}

Artigo recebido em 19/06/2013 e aceito para publicação em 05/09/2013

RESUMO: A evolução do federalismo brasileiro (fruto da influência e do poder das elites oligárquicas, dos diferentes textos constitucionais elaborados e das políticas de arrecadação de impostos) aponta uma das formas de como o Estado brasileiro usa o território para efetivar o exercício do poder. No país, este uso se realiza por meio da imposição de normas que regulam e geram tensões entre os entes, sendo que os mecanismos de distribuição e de redistribuição de recursos entre os entes federados adquirem grande importância por permitirem uma maior ou menor autonomia na administração pública. $\mathrm{O}$ texto objetiva analisar como tomam forma os convênios do Governo Federal para os municípios brasileiros. Tais convênios funcionam como um mecanismo que pode se configurar em promotor de novas seletividades e hierarquias entre os lugares. Com o intuito de compreender a materialização dos recursos públicos no território, nossa análise busca apontar como o Estado brasileiro faz uso de mecanismos constitucionais para ampliar e melhorar as infraestruturas urbanas na escala municipal.

Palavras-chave: território usado, desigualdade socioespacial, federação brasileira, políticas públicas.

ABSTRACT: The evolution of Brazilian federalism (result of the influence and power of oligarchic elites, the different constitutional texts made and policies designed to collect taxes) shows one of the forms of how the Brazilian government uses the territory to effect the exercise of power. In the country, this use takes place by the imposition of rules that regulate and create tension among the entities, and mechanisms of distribution and redistribution of resources among federal agencies acquire great importance because they allow a bigger or lesser autonomy in public administration. The text aims to analyze the voluntary transfers of resources from the Federal Government to the municipalities. These Covenants act as a mechanism that can be configured in promoter of new selectivity and hierarchies between places. With the aim to understand the materialization of public resources in the territory, our analysis intends to identify how the Brazilian government makes use of constitutional mechanisms to enlarge and improve the urban infrastructure in the municipal scale.

Keywords: used territory, sociospatial inequality, Brazilian federation, public policies. 
Território, política e infraestruturas: a influência do Governo Federal na política urbana dos municípios brasileiros Fabricio Gallo

\section{INTRODUÇÃO}

A interpretação geográfica de um território deve encontrar um método de pesquisa que considere os diversos aspectos da realidade. Para tanto, o partido de método adotado neste texto é o do território usado (SANTOS et al., 2000; SANTOS e SILVEIRA, 2001; SANTOS, 2005; SILVEIRA, 2008). Segundo tal perspectiva o território deve ser interpretado como uma concreção do espaço geográfico, compreendido aqui como um conjunto indissociável, solidário e contraditório, de sistemas de objetos e sistemas de ações (SANTOS, 2002).

Entendemos que na proposição de Santos $(2005$, p. 138) "o território são formas, mas território usado são objetos e ações, sinônimo de espaço humano, espaço habitado", assim, um ponto relevante na interpretação geográfica do território é distinguir os agentes da ação (aqueles que detêm o poder para usar esse território e atingir seus objetivos finais), pois na análise do território usado há que se considerar sempre a interdependência e inseparabilidade entre a materialidade e seu uso. Tal construção teórica é reafirmada por Silveira (2008, p. 3) para quem o território usado não é uma coisa inerte ou um palco onde a vida se desenvolve, ao contrário, é um quadro de vida, híbrido de materialidade e de vida social.

No Brasil observa-se uma difusão seletiva do meio técnico-cientifico-informacional (SANTOS, 2002) e, na busca de elementos que ajudem a compreender as desigualdades socioespacias apresentadas no país, há que se identificar os diferentes poderes que têm os agentes em usar o território. Desta forma, identificamos agentes que tem poder de ação no território como um todo (os agentes hegemônicos) e aqueles cujo poder de usar o território é mais limitado espacial e temporalmente, estes são os agentes hegemonizados. Para estes últimos o território seria seu abrigo, já para os primeiros o território seria um recurso - mas também abrigo (GOTTMANN, 2013).

$\mathrm{O}$ agente hegemônico por excelência no uso do território é o Estado e, organizado no Brasil em estrutura federativa desde 1891, este apresenta três níveis: União, estados-membros (e Distrito
Federal) e os municípios. Convém lembrar que o princípio federativo parte da premissa de que todos são iguais entre si sem que haja qualquer hierarquia. Na interpretação de Sanguin (1977) o Estado federal implica aliança, contrato ou pacto entre regiões e populações diversas. O regime federal de governo seria um fenômeno do direito constitucional onde a autoridade do Estado não é hierarquizada, mas compartilhada entre outros dois governos - ou três, como no caso brasileiro - em que cada um, nos limites de sua competência, exercem a plenitude dos poderes estatais.

A relevância do estudo sobre o federalismo nas ciências sociais, sobretudo na geografia, levou Saguin (1977) a afirmar que duas razões autorizam considerar o federalismo como a expressão mais geográfica de todas as formas de governo. Inicialmente o federalismo é fundado sobre um processo no qual um sentido de solidariedade social seria reconciliado com o compromisso de uma identidade local, através de uma organização política dualista. Depois, em razão dessa organização política dualista e da autonomia regional substancial, as regiões permanecem altamente articuladas, assim as interações espaciais num Estado federal são claramente e facilmente reconhecíveis. Dessa forma, o federalismo seria uma arquitetura política que visa resolver o problema da organização do poder em face das diversidades regionais, ou seja, seu desafio particular consiste em encontrar soluções para questões governamentais numa complexa relação de diferenças e semelhanças espaciais.

A Constituição Federal brasileira de 1988 garantiu - além da isonomia entre os entes - autonomia e competências exclusivas para tratar de determinados assuntos, estabelecidos constitucionalmente como próprios a cada ente. Entretanto, essas competências exclusivas também se estenderam à matéria tributária, assim, cada ente ficou com competência exclusiva de tributar sobre determinado campo. Desta forma, a União com poder de ação sobre toda a circunscrição do território nacional é o ente que mais arrecada impostos. Devido a essa desigualdade na arrecadação de impostos existem mecanismos intergovernamentais de distribuição de recursos, dos quais se destacam: (i) as transferên- 
cias constitucionais e legais (com regras previstas na Constituição Federal e em Leis e Decretos Federais) onde todos os entes têm asseguradas suas parcelas de recursos vindos de outros, e, (ii) as transferências voluntárias das quais se destacam os Convênios para ações diversas, formalizados entre a União e os estados e municípios e entre os estados e os municípios (CGU, 2005). Nesta última modalidade de transferências - as voluntárias - todos os entes podem pleitear recursos, todavia, isso não garante a formalização do Convênio, tampouco a liberação do dinheiro indicado em um Convênio assinado.

\section{A AMPLIAÇÃO SELETIVA DAS MATERIA- LIDADES NO TERRITÓRIO E O PAPEL DA UNIÃO COMO PROVEDORA DE RECURSOS POR MEIO DE CONVÊNIOS}

A Constituição de 1988 inseriu um aperfeiçoamento nos mecanismos de transferências intergovernamentais através do predomínio de regras e metodologias de arrecadação e distribuição definidas constitucionalmente e legalmente.

O Quadro 1 apresenta como está estruturada a competência de arrecadação de tributos no Brasil, vigente desde a promulgação da Constituição Federal de 1988.

Quadro 1. Brasil: competência de arrecadação de tributos na Constituição da República Federativa do Brasil de 1988

\begin{tabular}{|c|c|c|}
\hline União & Estados & Municípios \\
\hline $\begin{array}{ll}\text { - } & \text { Imposto sobre importação; } \\
\text { - } & \text { Imposto sobre exportação; } \\
\text { - } & \text { Imposto de renda; } \\
\text { - } & \text { Imposto sobre produtos industria- } \\
& \text { lizados; } \\
\text { - } & \text { Imposto sobre operações financei- } \\
& \text { ras; } \\
\text { - } & \text { Imposto territorial rural*; } \\
\text { - } & \text { Imposto sobre grandes fortunas } \\
& \text { (previsto na Constituição, mas ainda } \\
& \text { não instituído); } \\
\text { - } & \text { Taxas; } \\
\text { - Contribuições de melhoria }\end{array}$ & $\begin{array}{l}\text { - Imposto sobre transmissão de } \\
\text { propriedade "causa mortis"; } \\
\text { - Imposto sobre circulação de } \\
\text { mercadorias e serviços de trans- } \\
\text { porte e comunicação; } \\
\text { - Imposto sobre propriedade de } \\
\text { veículos automotores; } \\
\text { - Taxas; } \\
\text { - Contribuições de melhoria }\end{array}$ & $\begin{array}{l}\text { - Imposto sobre a propriedade } \\
\text { - } \quad \text { impredial e territorial urbana; } \\
\text { quer natureza; } \\
\text { - } \quad \text { Imposto sobre transmissão de } \\
\text { propriedade imobiliária "inter } \\
\text { vivos"; } \\
\text { - Imposto sobre vendas a varejo } \\
\text { de combustíveis líquidos e } \\
\text { gasosos (exceto óleo diesel); } \\
\text { Taxas; } \\
\text { - Contribuições de melhoria }\end{array}$ \\
\hline
\end{tabular}

Fonte: Adaptado de Gallo (2011).

* A responsabilidade pela cobrança deste imposto pode ser repassada aos municípios se estes se dispuserem a fazê-la.

No texto da Constituição de 1988 há a consolidação da tendência à descentralização fiscal que surgiu em fins da década de 1970, como resposta à excessiva concentração de recursos fiscais na esfera federal - fato que caracterizou o regime militar que já vinha apresentando indícios de enfraquecimento. Tal processo tratou-se de uma descentralização das receitas, fato que proporcionou o crescimento considerável da participação dos municípios nas receitas disponíveis.

Tem-se que no Texto Constitucional de 1988 o que se observou foi um processo de municipalização, ou seja, foi no nível municipal que se ampliaram os recursos de transferências intergovernamentais. Desta forma, pode-se dizer que esse crescimento é oriundo mais das transferências que as municipalidades recebem de outros entes do que de sua própria capacidade de arrecadação tributária.

A União, que perdeu recursos para estados e municípios após 1988, passou a recompor (desde meados da década de 1990) sua arrecadação através da imposição de contribuições sociais cumulativas de receita privativa, mas nunca novos impostos e que, portanto, constitucionalmente não têm que ser repassados aos entes da federação nos moldes redistributivos do FPE e FPM (ARRETCHE, 2005). 
Acerca disso, Oliveira (1995) lembra que à União ampliou-se o espaço que lhe foi reservado para aumentar a sua captação de recursos através do poder de criar impostos e contribuições sociais, de intervenção no domínio econômico e de interesse das categorias profissionais ou econômicas, como instrumento de sua atuação nas respectivas áreas.

Almeida (2005) lembra que as contribuições sociais, que em 1980 significavam 4,9\% das receitas do governo federal, atingiram $20 \%$ em 2000 . O mesmo apontamento é mencionado por Ângela Santos (2004, p. 4) ao afirmar que

após a entrada em vigor da Constituição Federal de 1988, houve uma forte reação da União federal ao aumento das receitas de transferências em favor dos municipios, o que teria caracterizado um processo de "municipalização das receitas". A partir dai, vem ocorrendo a recomposição das finanças do governo central mediante a criação de contribuições, receitas não partilháveis com os Estados e Municipios, que, ademais, sustentam os compromissos financeiros do governo num contexto de estagnação econômica.

A criação da CIDE-Combustíveis (Contribuição de Intervenção no Domínio Econômico sobre Combustíveis) em 2001, mais a criação da CPMF (Contribuição Provisória sobre Movimentação ou Transmissão de Valores e de Créditos e Direitos de Natureza Financeira) que vigorou de 1997 a 2007, somadas à ampliação das alíquotas de contribuições federais - Contribuição Social sobre o Lucro Líquido (CSLL), Contribuição para o Financiamento da Seguridade Social (COFINS) e Imposto sobre Operações Financeiras (IOF) - permitiram uma elevação substancial da arrecadação do governo federal. Desta forma, mesmo tendo perdido recursos na Constituição de 1988, a União, logo em seguida, começou a recompor sua estrutura orçamentária por meio da imposição de contribuições que não eram, obrigatoriamente, repartidas com os entes subnacionais.
Essa nova forma de recompor seu orçamento garantiu à União um aporte maior de recursos para, entre outras coisas, formalizar mais Convênios com os entes subnacionais - especialmente os municípios - aumentando assim a capacidade de ampliar sua influência política nessas esferas de governo subnacional. Soma-se a isso um "agravante": a União exige contrapartida dos municípios, ou seja, usa parte das receitas municipais para a realização de seus projetos.

A Controladoria-Geral da União (CGU), por meio do Portal da Transparência, disponibiliza os dados brutos referentes à formalização de Convênios, para gastos de todas as naturezas, da União com municípios a partir do ano de 1996. Se analisarmos a relação entre os valores conveniados e os valores que efetivamente foram liberados verificaremos que entre esses dois há um descompassado. Na Tabela 1 podemos observar esta relação com dados de 1996 a 2008, sendo que a opção por tratar dados até 2008 (nesta e nas tabelas seguintes) foi porque esta era base com dados consolidados e disponibilizados pela CGU à época da confecção das tabelas. 
Território, política e infraestruturas: a influência do Governo Federal na política urbana dos municípios brasileiros

Tabela 1. Brasil - Total dos Convênios, para gastos de todas as naturezas, entre União e municípios

\begin{tabular}{|c|c|c|c|c|c|}
\hline \multirow[b]{2}{*}{$\stackrel{\varrho}{\xi}$} & \multirow{2}{*}{ 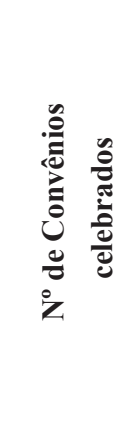 } & \multicolumn{2}{|c|}{$\begin{array}{l}\text { Valores dos Convênios referentes aos anos cor- } \\
\text { rentes }(1996-2008)\end{array}$} & \multicolumn{2}{|c|}{$\begin{array}{c}\text { Valores dos Convênios referentes aos anos cor- } \\
\text { rentes (1996-2008), mas que sofreram correção } \\
\text { monetária pelo IPC-A }\end{array}$} \\
\hline & & $\begin{array}{l}\text { Valores que foram } \\
\text { conveniados }\end{array}$ & $\begin{array}{l}\text { Valores } \\
\text { efetivamente } \\
\text { liberados } \\
\text { (B) }\end{array}$ & $\begin{array}{l}\text { Valores que foram } \\
\text { conveniados } \\
\text { (A + correção mone- } \\
\text { tária pelo IPC-A em } \\
\text { junho de } 2013)\end{array}$ & $\begin{array}{c}\text { Valores efetivamente } \\
\text { liberados } \\
\text { (B + correção mone- } \\
\text { tária pelo IPC-A em } \\
\text { junho de } 2013 \text { ) }\end{array}$ \\
\hline 1996 & 16.720 & $6.383 .565 .738,89$ & $5.964 .351 .064,30$ & 19.064.812.082,20 & $17.812 .808 .216,35$ \\
\hline 1997 & 18.234 & $4.687 .466 .788,34$ & $4.221 .927 .614,59$ & $12.777 .335 .094,04$ & $11.508 .344 .764,16$ \\
\hline 1998 & 29.084 & 7.867.212.511,22 & $7.109 .200 .258,41$ & $20.380 .044 .691,87$ & $18.416 .410 .994,23$ \\
\hline 1999 & 14.969 & $7.837 .398 .710,08$ & $6.682 .568 .537,86$ & $19.972 .144 .235,14$ & $17.029 .275 .607,97$ \\
\hline 2000 & 22.606 & $8.330 .697 .630,51$ & $7.728 .503 .713,06$ & $19.487 .091 .253,68$ & $18.078 .444 .783,22$ \\
\hline 2001 & 21.940 & $9.456 .783 .068,88$ & $8.577 .187 .858,29$ & $20.874 .128 .433,77$ & $18.932 .582 .006,06$ \\
\hline 2002 & 35.580 & $12.867 .576 .349,33$ & $10.815 .783 .800,54$ & $26.378 .725 .815,85$ & $22.172 .520 .108,34$ \\
\hline 2003 & 15.871 & $6.315 .054 .068,78$ & $5.470 .702 .997,93$ & $11.504 .414 .384,08$ & $9.966 .222 .548,85$ \\
\hline 2004 & 22.159 & $11.033 .189 .350,83$ & $9.760 .500 .181,35$ & $18.389 .441 .467,43$ & $16.268 .201 .430,93$ \\
\hline 2005 & 22.459 & $10.474 .177 .321,27$ & $9.055 .413 .380,79$ & $16.224 .544 .661,77$ & $14.026 .873 .358,36$ \\
\hline 2006 & 31.994 & $15.006 .967 .857,39$ & $11.438 .908 .201,52$ & $21.994 .432 .693,65$ & $16.765 .032 .011,34$ \\
\hline 2007 & 21.026 & $15.824 .941 .042,59$ & $10.565 .691 .537,70$ & $22.486 .780 .714,90$ & $15.013 .540 .212,45$ \\
\hline 2008 & 32.479 & $18.242 .767 .612,87$ & $6.511 .839 .020,39$ & $24.816 .298 .995,07$ & $8.858 .290 .998,66$ \\
\hline Total & 305.121 & $134.327 .798 .050,98$ & $103.902 .578 .166,73$ & $254.350 .194 .523,45$ & $204.848 .547 .040,92$ \\
\hline
\end{tabular}

Fonte dos dados: Portal da Transparência do governo federal do Brasil.

Organização do autor.

É conveniente mencionar que os valores da Tabela 1 apontados nas colunas "(A)" e "(B)" são aqueles correntes apresentados pela Controladoria-Geral da União em seu site na internet e não sofreram correção monetária; já as colunas expressas como "(A + correção monetária pelo IPC-A em junho de 2013)" e "(B + correção monetária pelo IPC-A em junho de 2013)" apresentam os valores indicados nas colunas (A) e (B) atualizados, para nossos dias, através da ferramenta "Calculadora do Cidadão" do site do Banco Central do Brasil, pois, tal ferramenta, permite a correção de valores com base em diversos indicadores econômicos.

Em nosso caso utilizamos a atualização pelo IPC-A (Índice de Preços ao Consumidor Amplo) do Instituto Brasileiro de Geografia e Estatística (IBGE). Este índice é aquele utilizado oficialmente para a medição da inflação no Brasil sendo, também, a referência para cálculos de atualizações monetárias.
Consideradas essas ressalvas, apontamos que o intuito com todos esses valores da Tabela 1 é elaborar uma comparação entre os valores que foram empenhados (conveniados) ao longo dos anos e aquilo que efetivamente fora liberado. Igualmente, há que apontar outro elemento importante: além de visualizarmos os valores dos Convênios celebrados, temos que nos atentar para o número de Convênios que foram firmados. De 1996 a 2008 há uma tendência ao aumento do número de Convênios assinados: em 1996 foram 16.720 e, em 2008, foi quase o dobro, 32.479. Destaca-se que nos anos de eleições majoritárias existem picos nesta série de crescimento: em 1998 foram 29.084; em 2002, salta para 35.580; e em 2006 o número foi de 31.994.

Outrossim, a leitura da Tabela 1 permite observar que os valores conveniados e liberados apresentam dois períodos distintos: de 1996 a 2002, período selecionado do governo do presidente Fernando Henrique 
Território, política e infraestruturas: a influência do Governo Federal na política urbana dos municípios brasileiros Fabricio Gallo

Cardoso (FHC) do Partido da Social Democracia Brasileira (PSDB) e de 2003 a 2008, período de governo do presidente Luiz Inácio Lula da Silva (Lula) do Partido dos Trabalhadores (PT).

No período FHC, analisando as colunas com valores corrigidos, percebe-se que em praticamente todos os anos cerca de $90 \%$ dos valores empenhados foram efetivamente liberados. Já na série relativa ao governo petista (2003 a 2008), nota-se um crescimento dos recursos conveniados (chegou a quase $\mathrm{R} \$ 22,4$ bilhões em 2007 e a pouco mais de $\mathrm{R} \$ 24,8$ bilhões em 2008), entretanto, diferentemente do seu antecessor, durante o governo Lula os valores efetivamente liberados foram menores que os empenhados: nos anos de 2003, 2004 e 2005 estes corresponderam cerca de $85 \%$ daquilo que foi empenhado. Já nos anos seguintes a redução da liberação foi mais significativa: em 2006, 2007 e 2008 as liberações significaram, respectivamente, $76 \%$, $66 \%$ e $35 \%$ daquilo que se empenhou ao se celebrarem os Convênios.

Quanto ao governo petista duas interpretações podem ser elencadas: a) a partir de 2007 o governo federal criou o PAC (Programa de Aceleração do Crescimento) que prevê grandes obras de infraestrutura, ou seja, grande quantidade de recursos. Os recursos liberados pelo PAC ocorrem de maneira gradual, isto quer dizer que um volume de recursos conveniado em 2007 para uma obra, pode ser liberado gradualmente ao longo de 1, 2 ou 3 anos, conforme o cronograma de execução da mesma; b) em 2008, durante a crise financeira mundial que afetou as economias de inúmeros países, o governo brasileiro cortou parte dos investimentos públicos da Presidência da República e em todos os Ministérios ocasionando uma retração nos investimentos públicos federais.

Os recursos de Convênios têm inúmeras finalidades: podem ser destinados a implantação de novas infraestruturas territoriais (de macrossistemas técnicos ao saneamento urbano ou construção de cisternas); servem à aquisição de veículos (ambulâncias, máquinas agrícolas e veículos em geral para uso do poder público ou de cooperativas), podem servir apoiando a implantação de ações específicas em localidades do interior do país (construção de casa de farinha na Amazônia e Nordeste, ações de implementação de pecuária caprina e bovina para suprimento familiar de leite em municípios do interior do Nordeste, entre tantos outros), servem para aquisição de material de consumo e material permanente, servem para financiar cursos de capacitação de pessoal das prefeituras e de instituições e existem até ações onde os Convênios financiam festas populares - pode-se citar os Ministérios do Turismo e da Cultura que celebram Convênios com municipalidades para financiar parte dos custos dos festejos juninos no Nordeste, parte dos recursos de festejos de carnaval, festas de réveillon, festivais de inverno, festas de rodeio, festas de cultura pantaneira etc.

O número total de Convênios celebrados entre União e municípios (de 1996 a 2008) foi 305.121, resultando num número médio anual de aproximadamente 23.470. Contudo, optamos por um recorte empírico que considera a geografização desses recursos de Convênios, ou seja, consideramos em nossa análise aqueles que se transformaram em materialidades ampliando assim a densidade técnica do território (SANTOS, 2002) provendo-o de novos objetos técnicos ou promovendo a melhoria dos existentes.

$\mathrm{Na}$ análise do território usado no Brasil, esse perfil material, ou infraestrutural, é

o fundamento dos valores de uso e dos valores de troca [...]. Pode-se dizer que, consideradas em sua realidade técnica e em seus regulamentos de uso, as infraestruturas "regulam" comportamentos e dessemodo "escolhem", "selecionam" os atores possiveis (SANTOS, 2002, p. 306).

Desde o ano 2000 o número de Convênios celebrados entre União e municípios apresentou crescimento, à exceção do ano de 2003 e 2004 quando sofrem leve redução. A Tabela 2 aponta todos os Convênios celebrados, os valores conveniados e os efetivamente liberados que visaram a ampliação da densidade técnica territorial. Os Convênios indicados na Tabela 2 foram aqueles que trouxeram na descrição de seu Plano de Trabalho variáveis territorializantes, como "pavimentações", "reformas", "ampliações", "melhorias" e "construções" de infraestruturas em geral.

Na Tabela 2 e no Gráfico 1 foram incluídos os recursos oriundos da Presidência da República (Casa Civil) e todos os Ministérios, exceto os da Educação e Saúde. Optou-se pela exclusão destes dois Ministérios 
Território, política e infraestruturas: a influência do Governo Federal na política urbana dos municípios brasileiros

das análises porque parte dos Convênios que celebram enquadram-se como Transferências Automáticas e Transferências fundo a fundo, ou seja, os Convênios são "renovados" automaticamente e para a manutenção do repasse dos recursos dos Convênios, não há a necessidade de se encaminhar às prefeituras novos planos de trabalhos, novas justificativas etc. Neste caso, basta apenas encaminhar corretamente as prestações de contas que os Convênios celebrados para que os mesmos sejam automaticamente renovados.

Tabela 2. Brasil - Convênios entre União* e municípios (destinados a ampliar as materialidades no território)

\begin{tabular}{|c|c|c|c|c|c|}
\hline \multirow[b]{2}{*}{$\stackrel{\varrho}{\varrho}$} & \multirow{2}{*}{ 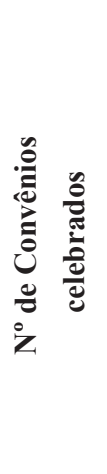 } & \multicolumn{2}{|c|}{$\begin{array}{c}\text { Valores dos Convênios referentes aos anos } \\
\text { correntes }(1996-2008)\end{array}$} & \multicolumn{2}{|c|}{$\begin{array}{l}\text { Valores dos Convênios referentes aos anos cor- } \\
\text { rentes (1996-2008) mas que sofreram correção } \\
\text { monetária pelo IPC-A }\end{array}$} \\
\hline & & $\begin{array}{l}\text { Valores que foram } \\
\text { conveniados } \\
\text { (A) }\end{array}$ & $\begin{array}{c}\text { Valores } \\
\text { efetivamente } \\
\text { liberados } \\
\text { (B) }\end{array}$ & $\begin{array}{l}\text { Valores que foram } \\
\text { conveniados } \\
\text { (A + correção mo- } \\
\text { netária pelo IPC-A } \\
\text { em junho de 2013) }\end{array}$ & $\begin{array}{c}\text { Valores efetivamente } \\
\text { liberados } \\
\text { (B + correção monetária } \\
\text { pelo IPC-A em junho de } \\
\text { 2013) }\end{array}$ \\
\hline 1996 & 924 & $1.041 .106 .878,26$ & $965.687 .736,69$ & $3.109 .313 .477,95$ & $2.893 .030 .386,33$ \\
\hline 1997 & 1.342 & $958.678 .196,26$ & $879.452 .957,88$ & $2.613 .213 .727,51$ & $2.397 .257 .546,40$ \\
\hline 1998 & 2.769 & $1.850 .332 .055,83$ & $1.590 .037 .887,49$ & $4.793 .292 .404,77$ & $4.118 .999 .347,42$ \\
\hline 1999 & 544 & $2.477 .059 .836,35$ & $1.733 .190 .133,34$ & $6.312 .323 .534,15$ & $4.416 .710 .774,08$ \\
\hline 2000 & 4.806 & $1.520 .843 .626,96$ & $1.408 .176 .792,17$ & $3.557 .543 .418,18$ & $3.293 .994 .196,62$ \\
\hline 2001 & 4.797 & $1.652 .919 .152,20$ & $1.553 .939 .964,86$ & $3.648 .518 .362,05$ & $3.430 .039 .808,85$ \\
\hline 2002 & 7.730 & $3.776 .316 .614,34$ & $3.241 .621 .586,85$ & $7.741 .506 .081,08$ & $6.645 .373 .199,79$ \\
\hline 2003 & 2.866 & $2.306 .176 .078,24$ & $1.821 .865 .164,62$ & $4.201 .263 .355,51$ & $3.318 .972 .660,07$ \\
\hline 2004 & 3.845 & $1.909 .718 .761,11$ & $1.721 .147 .398,85$ & $3.183 .001 .783,13$ & $2.868 .702 .632,42$ \\
\hline 2005 & 4.701 & $2.060 .878 .732,48$ & $1.881 .514 .616,10$ & $3.192 .309 .811,56$ & $2.914 .474 .042,55$ \\
\hline 2006 & 7.026 & 5.181.113.992,56 & $3.784 .979 .183,70$ & $7.593 .516 .829,05$ & $5.547 .321 .129,80$ \\
\hline 2007 & 6.362 & $6.069 .146 .830,45$ & $3.461 .481 .038,78$ & $8.624 .081 .033,26$ & $4.918 .663 .825,90$ \\
\hline 2008 & 10.565 & 7.778.349.662,13 & $2.466 .967 .997,05$ & $10.581 .171 .399,31$ & $3.355 .906 .117,26$ \\
\hline TOTAL & $\mathbf{5 8 . 2 7 7}$ & 38.582.640.417,17 & $26.510 .062 .458,38$ & $69.151 .055 .217,51$ & $50.119 .445 .667,49$ \\
\hline
\end{tabular}

Fonte: Portal da Transparência do governo federal do Brasil. Organização do autor. * Excluídos os Ministérios da Educação e da Saúde.

Considerando-se os Convênios destinados a ampliar as materialidades no território, nos últimos três anos do governo FHC (2000, 2001 e 2002) houve uma elevação no "número de Convênios celebrados" se comparados ao período de 1996 a 1999. O ano de 2003 foi emblemático porque a queda na quantidade de Convênios celebrados foi brusca: de 7.730 em 2002 para $2.866 \mathrm{em}$ 2003, primeiro ano do governo Lula.

A mudança de governo (saída de oito anos de governo PSDB para um governo do PT) implica novos acordos políticos, novas influências políticas e novas negociações entre os entes da federação.
Tanto o é que após 2003 o número de Convênios firmados volta à tendência de crescimento.

A Figura 1 apresenta a evolução dos valores dos Convênios destinados à ampliação da densidade técnica no território e os recursos que efetivamente foram liberados. 
Território, política e infraestruturas: a influência do Governo Federal na política urbana dos municípios brasileiros Fabrício Gallo

Figura 1. Brasil - Recursos de Convênios infraestruturais celebrados entre União e municípios (excluídos os Ministérios da Educação e da Saúde)

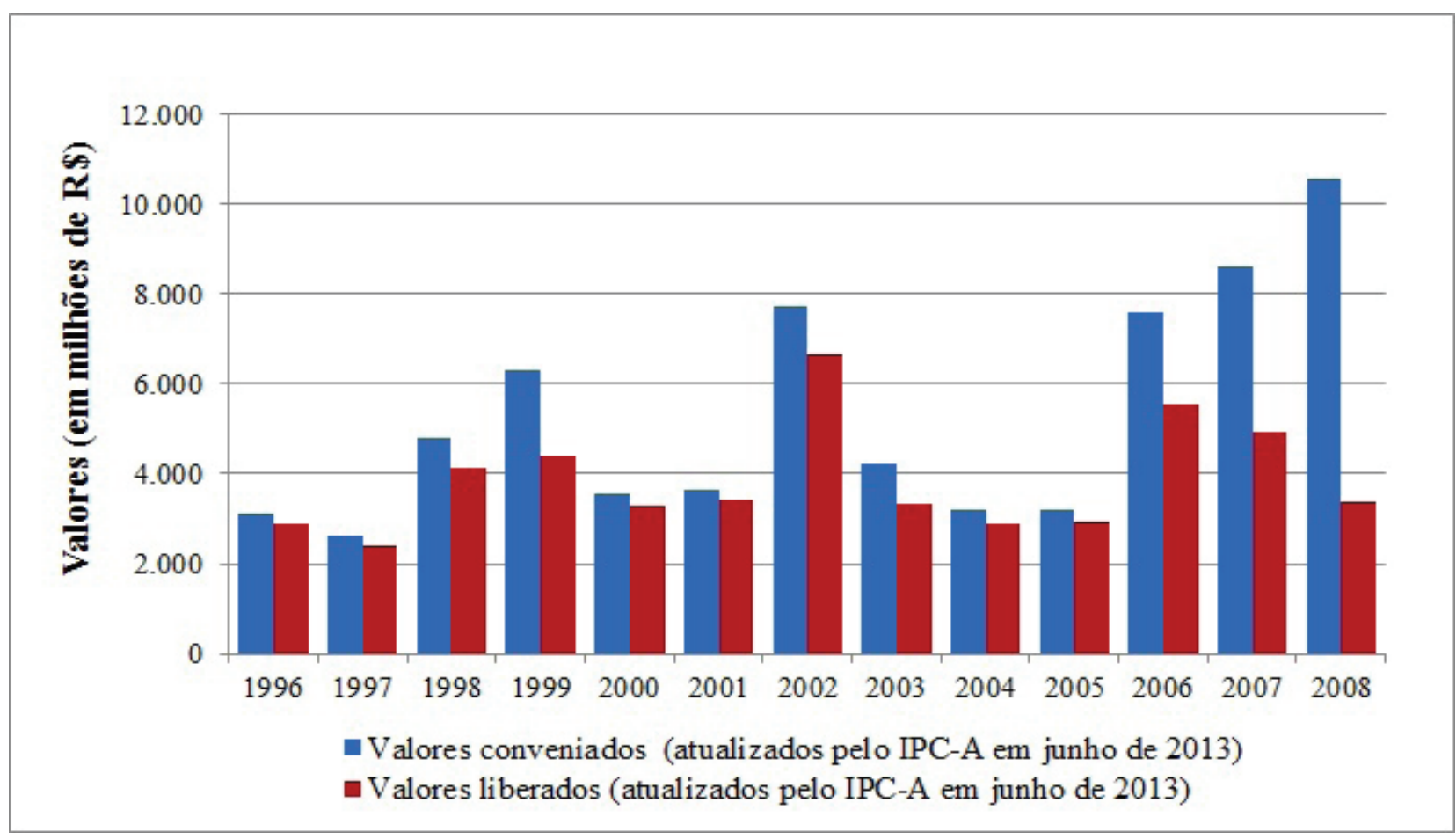

Fonte dos dados: Portal da Transparência do governo federal do Brasil.

Elaboração do autor.

A leitura da Figura 1 chama atenção para o período de 1996 a 1999. Neste período o número de Convênios celebrados foi pequeno se compararmos com os outros anos (houve, em média 1.300 convênios firmados por ano neste período), mas se observada a correção monetária dos valores conveniados e liberados percebe-se que os anos de 1998 e 1999 os recursos envolvidos foram os maiores da série FHC, atrás apenas do ano de 2002 - ano de disputa eleitoral que marcaria o final dos 2 mandatos do presidente peessedebista. Os valores liberados em 1998 e 1999 foram, respectivamente, $\mathrm{R} \$ 4.118 .999 .347,42$ e $\mathrm{R} \$$ 4.416.710.774,08 (conforme a Tabela 2 e observadas a atualização monetária). Ainda do ano de 1998 para 1999 houve uma redução no número de Convênios assinados (de 2.769 para 544), porém os valores desses Convênios foram mais significativos se comparados com os anos anteriores. Já em 2000 e 2001 vê-se um aumento no número de Convênios celebrados: os números são de aproximadamente $4.800 \mathrm{em}$ cada ano, todavia, os valores liberados ficaram abaixo de 1998 e 1999, ou seja, houve um aumento do número de
Convênios assinados, mas os valores não cresceram proporcionalmente, supostamente porque houve um aumento do número de Convênios de menores valores.

No ano de 2002 (último do governo FHC) há um expressivo aumento do número de Convênios celebrados, dos valores empenhados e dos valores efetivamente liberados: foram 7.730 Convênios e pouco mais de $\mathrm{R} \$$ 6,5 bilhões liberados (maiores números do governo FHC, conforme a atualização monetária). Neste ano a disputa presidencial foi um dos motivos que levou à expressiva utilização dos Convênios como mecanismos para fazer a "máquina federal" chegar aos lugares.

Conforme as informações constantes na Tabela 2, se novamente nos ativermos aos dados dos valores corrigidos, em 2003 há uma significativa queda nos valores conveniados (caindo, da faixa dos $\mathrm{R} \$ 7,7$ bilhões em 2002, para R \$ 4,2 bilhões em 2003). Entretanto, a partir de 2003 os valores se mantêm na faixa de R \$3,1 bilhões anuais até o ano 2005. Já a partir de 2006 há um expressivo aumento nos valores conveniados ficando em aproximadamente $\mathrm{R} \$$ 7,5 bilhões em 2006, R \$ 8,6 bilhões em 2007 e R\$ 
10,5 bilhões em 2008. Em se tratando dos recursos efetivamente liberados, entre 2006 e 2008 há uma redução: foram liberados pouco mais de $\mathrm{R} \$ 5,5$ bilhões em 2006, cerca de R $\$ 4,9$ bilhões em 2007 e R \$ 3,3 bilhões em 2008. Pode-se apontar que os motivos que ocasionaram essa redução podem ser os mesmos apontados anteriormente, nas reflexões sobre a Tabela 1, a saber: seriam a crise econômica de 2008 (que ocasionou a retração dos investimentos públicos) e a formalização do PAC - Programa de Aceleração do Crescimento (e seus mecanismos de liberação de recursos de forma parcial, isto é, acompanhando o ritmo de cada etapa no planejamento das obras ou ações ligadas à infraestrutura).

\section{A GEOGRAFIZAÇÃO DOS CONVÊNIOS: A APLICAÇÃO DOS RECURSOS PÚBLICOS NA PROMOÇÃO DAS DISTINTAS POLÍTICAS FEDERAIS DE FHC E LULA}

O aumento ou redução do número de Convênios celebrados, dos valores conveniados e dos valores que foram efetivamente liberados (elementos observados através da análise do Gráfico 1) não são elementos suficientes para uma análise geográfica que se proponha a entender a distribuição desses recursos no território brasileiro. Assim, para tentarmos lançar luz sobre como se processam os acordos políticos que regem as solidariedades federativas no país, faz-se necessária uma espacialização desses dados com o intuito de localizar o destino dos recursos liberados pela União.
A Tabela 3 apresenta os dados referentes aos Convênios destinados às infraestruturas urbanas durante parte do governo (aqueles Convênios que se referiam à construção, ampliação ou reformas: de casas populares em programas de habitação, de galpões, de ginásios e quadras poliesportivas e campos e estádios de futebol, de praças, de mercados municipais, de postos médicos e postos policiais e em obras de calçamento e pavimentação de vias urbanas, assim como a manutenção e construção de guias e sarjetas). 
Território, política e infraestruturas: a influência do Governo Federal na política urbana dos municípios brasileiros Fabrício Gallo

Tabela 3. Convênios destinados às infraestruturas urbanas (valores conveniados, valores liberados e número de municípios contemplados)

\begin{tabular}{|c|c|c|c|c|c|c|}
\hline \multirow{2}{*}{$\begin{array}{c}\text { UF's e } \\
\text { Regiões } \\
\text { do IBGE }\end{array}$} & \multicolumn{3}{|c|}{$\begin{array}{c}\text { Período FHC } \\
\text { (dados de 01/01/1996 a 31/12/2002) }\end{array}$} & \multicolumn{3}{|c|}{$\begin{array}{c}\text { Período LULA } \\
(\text { dados de } 01 / 01 / 2003 \text { a } 31 / 12 / 2008)\end{array}$} \\
\hline & \begin{tabular}{|c|}
$\mathrm{N}^{\mathrm{o}} \mathrm{de}$ \\
Municípios
\end{tabular} & $\begin{array}{c}\text { Valores } \\
\text { conveniados } \\
(\mathrm{em} \mathrm{R} \$)\end{array}$ & $\begin{array}{c}\text { Valores } \\
\text { liberados } \\
(\mathrm{em} \mathrm{R} \$)\end{array}$ & $\begin{array}{c}\mathrm{N}^{\mathrm{o}} \mathrm{de} \\
\text { Municípios }\end{array}$ & $\begin{array}{c}\text { Valores } \\
\text { conveniados } \\
(\mathrm{em} \mathrm{R} \$)\end{array}$ & $\begin{array}{c}\text { Valores } \\
\text { liberados } \\
(\mathrm{em} \mathrm{R} \$)\end{array}$ \\
\hline $\mathbf{A C}$ & 15 & 7.434 .093 & 7.186 .102 & 14 & 18.495 .251 & 12.797 .604 \\
\hline $\mathbf{A M}$ & 44 & 33.455 .114 & 33.285 .114 & 48 & 177.011 .701 & 97.903 .939 \\
\hline $\mathbf{A P}$ & 9 & 23.535 .096 & 20.404 .096 & 11 & 105.764 .607 & 57.899 .378 \\
\hline $\mathbf{P A}$ & 63 & 41.964 .304 & 41.409 .868 & 84 & 276.557 .939 & 160.878 .252 \\
\hline RO & 38 & 55.851 .742 & 52.979 .162 & 45 & 125.267 .485 & 71.035 .597 \\
\hline $\mathbf{R R}$ & 15 & 50.003 .784 & 49.803 .784 & 15 & 146.446 .979 & 101.076 .079 \\
\hline TO & 63 & 20.320 .551 & 19.881 .631 & 113 & 177.525 .333 & 95.183 .094 \\
\hline Reg. N & 247 & 232.564 .685 & 224.949 .757 & 330 & 1.027 .069 .294 & 596.773 .943 \\
\hline AL & 56 & 27.679 .400 & 27.679 .400 & 84 & 281.761 .114 & 160.248 .013 \\
\hline $\mathbf{B A}$ & 172 & 91.399 .247 & 86.847 .247 & 258 & 517.609 .724 & 296.408 .006 \\
\hline CE & 87 & 35.840 .894 & 34.999 .936 & 162 & 278.535 .119 & 222.441 .420 \\
\hline MA & 85 & 15.894 .553 & 15.419 .622 & 172 & 221.299 .987 & 138.401 .091 \\
\hline PB & 156 & 97.513 .649 & 92.316 .678 & 185 & 255.761 .160 & 119.312 .078 \\
\hline $\mathbf{P E}$ & 85 & 61.616 .205 & 58.051 .115 & 144 & 399.287 .731 & 178.350 .379 \\
\hline PI & 161 & 61.591 .909 & 61.406 .712 & 186 & 150.883 .801 & 121.090 .542 \\
\hline RN & 135 & 68.632 .913 & 64.886 .942 & 152 & 175.853 .819 & 139.803 .583 \\
\hline SE & 30 & 37.156 .885 & 35.929 .208 & 66 & 101.701 .608 & 76.491 .261 \\
\hline Reg. NE & 967 & 497.325 .655 & 477.536 .861 & 1.409 & 2.382 .694 .063 & 1.452 .546 .371 \\
\hline DF & 1 & 11.814 .893 & 3.627 .781 & 1 & 135.321 .991 & 67.160 .687 \\
\hline GO & 78 & 96.479 .880 & 95.979 .880 & 187 & 288.197 .246 & 199.740 .650 \\
\hline MS & 60 & 50.190 .659 & 50.164 .216 & 76 & 186.497 .639 & 110.265 .988 \\
\hline MT & 99 & 90.151 .270 & 86.177 .050 & 77 & 282.062 .172 & 117.312 .744 \\
\hline Reg. C-O & 238 & 248.636 .701 & 235.948 .927 & 341 & 892.079 .048 & 494.480 .069 \\
\hline ES & 38 & 15.241 .433 & 15.241 .433 & 68 & 71.895 .188 & 48.755 .762 \\
\hline MG & 318 & 85.019 .243 & 84.122 .248 & 668 & 418.167 .851 & 216.418 .685 \\
\hline RJ & 44 & 44.447 .167 & 38.889 .105 & 79 & 365.058 .275 & 204.196 .077 \\
\hline SP & 197 & 79.708 .240 & 79.468 .805 & 547 & 474.478 .714 & 227.228 .861 \\
\hline Reg. SE & 597 & 224.416 .083 & 217.721 .592 & 1.362 & 1.329 .600 .028 & 696.599 .384 \\
\hline PR & 191 & 35.929 .707 & 35.815 .707 & 322 & 206.724 .083 & 143.600 .628 \\
\hline RS & 146 & 22.313 .848 & 22.132 .859 & 415 & 208.946 .948 & 109.737 .949 \\
\hline SC & 191 & 83.912 .731 & 83.565 .387 & 261 & 242.747 .749 & 174.449 .124 \\
\hline Reg. S & 528 & 142.156 .286 & 141.513 .953 & 998 & 658.418 .780 & 427.787 .701 \\
\hline $\begin{array}{c}\text { TOTAL } \\
\text { das UF's (sem correção } \\
\text { monetária) }\end{array}$ & \multirow{2}{*}{2.577} & 1.345.099.410 & 1.297.671.089 & \multirow{2}{*}{4.440} & 6.289 .861 .213 & 3.668 .187 .470 \\
\hline $\begin{array}{c}\text { TOTAL } \\
\text { das UF's (com correção } \\
\text { monetária pelo IPC-A) }\end{array}$ & & 4.017.201.128 & 3.875.554.270 & & 11.458.519.441 & 6.682.499.981 \\
\hline
\end{tabular}

Fonte dos dados: Portal da Transparência do governo federal do Brasil.

Organização do autor. 
Os dados da Tabela 3 apontam que no período Lula o "número de municípios" que receberam recursos de Convênios foi maior em todas as regiões do país. Se nos atentarmos para o volume total de recursos liberados (com valores corrigidos pelo IPC-A) percebe-se que este foi quase duas vezes maior durante o governo petista se comparado ao governo do PSDB. Foram R \$ 3.875.554.270,00 no período FHC e R\$ 6.682.499.981,00 ao longo do período Lula.

O que mais se destaca nesta Tabela 3 é a política de ampliação do número de municípios beneficiados com recursos destinados às infraestruturas urbanas: em todas as regiões do país o número de municípios recebedores cresceu. Nos anos de governo peessedebista foram 2.577 municípios contra 4.440 no governo petista. Este número representa um aumento de $72 \%$, além disso, houve crescimento em todas as 5 regiões, todavia, as regiões Sudeste e Sul tiveram um crescimento bem superior às outras. Na Região Norte, aumento de 33\%; na Região Nordeste, acréscimo de 45\%; na Região Centro-Oeste a ampliação foi de 43\%; na Região Sudeste o aumento de $122 \%$ e na Região Sul esse crescimento foi de $89 \%$.

Abaixo mapeamos (Figuras 2 e 3 ) os dados da Tabela 3 no intuito de visualizar a espacialização dos recursos liberados pelos Convênios destinados aos investimentos federais em infraestruturas urbanas. Convém informar que, neste caso, os valores utilizados para o mapeamento foram aqueles que não sofreram correção, haja vista a inviabilidade de se fazer uso da ferramenta de atualização monetária nos dados de cada um dos estados brasileiros e em cada ano das séries históricas consideradas.

Figura 2. Distribuição espacial dos recursos (valores correntes) liberados por Convênios celebrados entre União e Municípios para obras de infraestrutura urbana durante período de governo FHC (dados de 01/01/1996 a 31/12/2002)

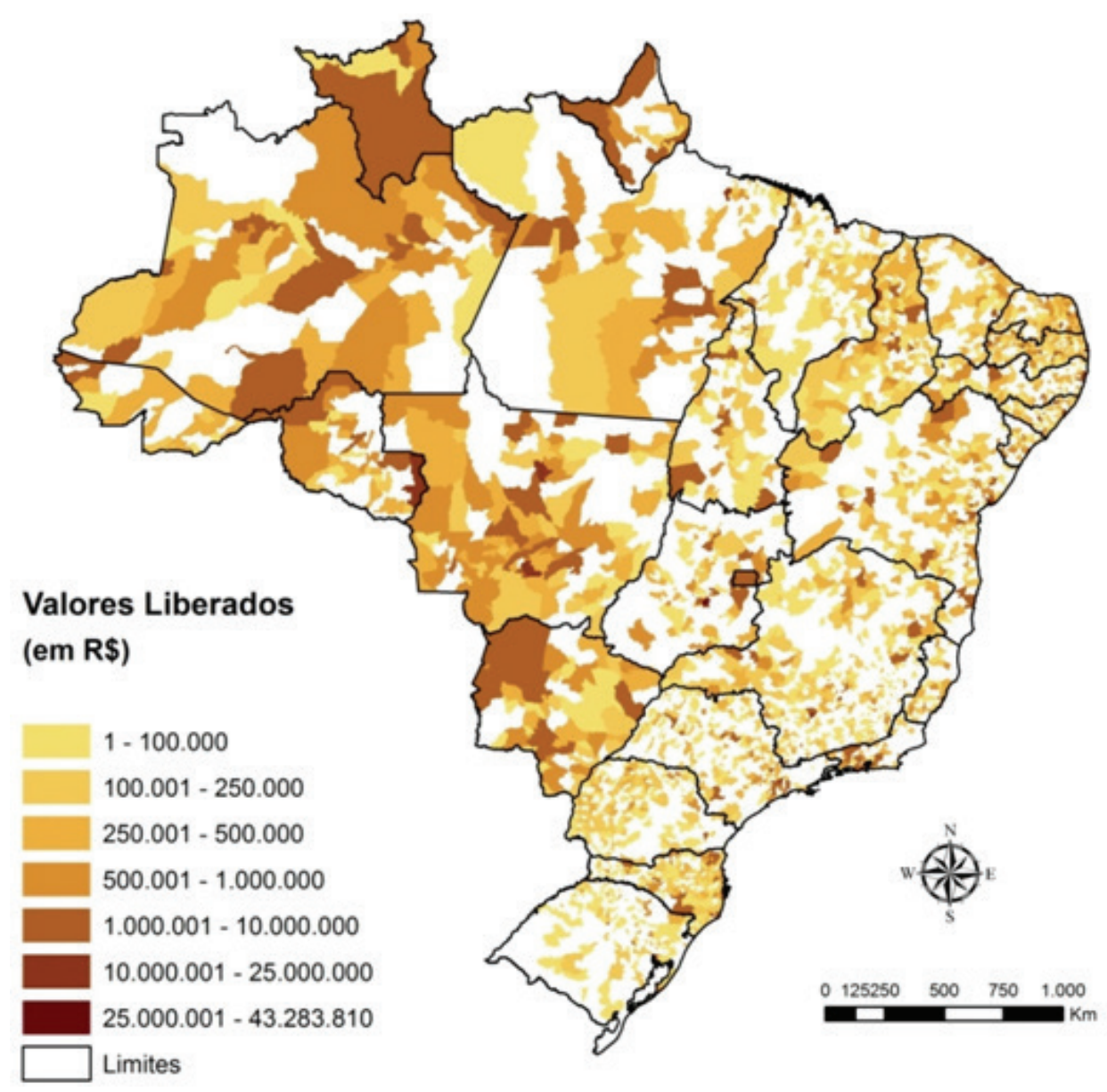

Fonte: Gallo (2011) 
Como mencionado anteriormente, durante o período analisado do governo FHC (dados de 01/01/1996 a 31/12/2002) foram 2.577 os municípios recebedores de recursos. Na escala do território nacional ganham destaque algumas regiões do país: Região Norte (dos 450 municípios que compõem a região, 247 receberam recursos) e a Região Centro-Oeste (dos 464 municípios, 238 tiveram verbas liberadas).
É relevante também destacar que algumas áreas do território nacional receberam aporte significativo de recursos: nos estados do Piauí, Paraíba e Rio Grande do Norte quase todos os municípios tiveram verbas liberadas, assim como a porção leste do estado de Santa Catarina.

Figura 3. Distribuição espacial dos recursos (valores correntes) liberados por Convênios celebrados entre União e Municípios para obras de infraestrutura urbana durante período de governo Lula (dados de $01 / 01 / 2003$ a $31 / 12 / 2008)$

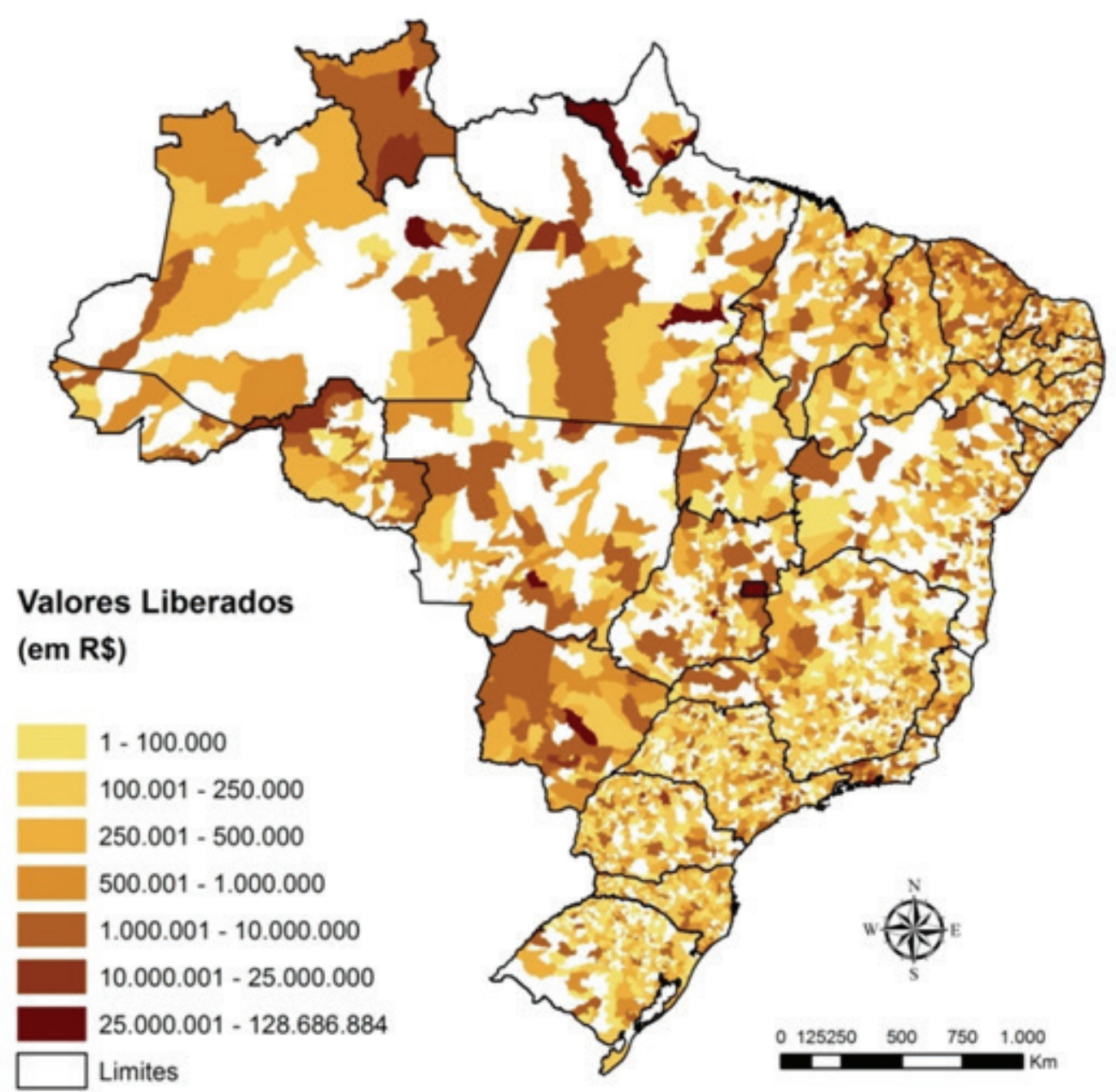

Fonte: Gallo (2011) 
Percebe-se na Figura 3 a ampliação do número de municípios beneficiados com recursos destinados às infraestruturas urbanas, entretanto nota-se que um número maior de municípios da Região Concentrada (SANTOS; RIBEIRO, 1979) recebeu recursos de Convênios se fizermos uma comparação com o período FHC (apontado pelo Mapa 1). Na exposição de Santos (1993) a Região Concentrada corresponderia a uma continua área onde a divisão do trabalho é mais intensa do que no resto do país. Este fato garante a presença conjunta das variáveis modernas ao passo que no resto do país a modernização é seletiva. Grosso modo, a Região Concentrada seria composta pelos estados do RS, SC, PR, SP, RJ, ES, MG (exceto sua porção norte), a parte leste do estado do MS e a porção sul do estado de GO.

No governo Lula, a opção por destinar mais investimentos à Região Concentrada apresenta-se como um demonstrativo do projeto deste governo para investir na área mais urbanizada do país. Durante o segundo governo do presidente Lula, o PAC destaca-se como pilar central do planejamento territorial brasileiro proposto dentro do Plano Plurianual (PPA) - que se estendeu de 2008 a 2011 - e que foi uma continuação da política de governo baseada nas propostas elencadas no PPA Brasil de Todos (2004-2007), do primeiro governo petista. Há que se ressaltar a importância de se analisar o chamado Plano Plurianual como ferramenta de planejamento porque o conjunto de tais planos de governo seriam, na leitura de Lessa et al. (2009, p. 97) "o principal instrumento do planejamento brasileiro, a ferramenta de ligação entre as intenções de médio prazo e a operacionalidade da máquina pública no curto prazo". No PPA do primeiro governo Lula - diferentemente dos outros dois anteriores do então presidente FHC, onde o planejamento territorial se pautava quase que exclusivamente na "política dos Eixos de Integração e Desenvolvimento"-, um elemento diferenciado foi incorporado ao seu texto. Segundo o documento:

numa perspectiva de longo prazo, objetiva-se com o PPA 2004-2007 inaugurar um processo de crescimento induzido pela expansão do mercado de consumo de massa com base na incorporação progressiva das famílias trabalhadoras ao mercado consumidor das empresas modernas (BRASIL, 2004).
Esta busca pela expansão da economia de massas baseada na expansão do comércio tem um claro apelo à necessidade de um melhor aparelhamento urbano, haja vista que o comércio de massas se pratica nas cidades. Um dos itens listados nos "Megaobjetivos" do PPA 20042007 propõe "implementar o processo de reforma urbana, melhorar as condições de habitabilidade, acessibilidade e de mobilidade urbana" (BRASIL, 2004), desta forma, é justificável esta ampliação dos investimentos federais no aparelhamento urbano dos municípios brasileiros (crescimento de $72 \%$ no número de municípios recebedores de recursos).

\section{CONSIDERAÇÕES FINAIS}

O estudo das transferências de recursos tributários por meio de Convênios é uma das formas de compreender como o Estado usa o território. No intuito de efetivar o exercício do poder, este uso é realizado por meio da imposição de normas que regulam e geram tensões entre os entes. A atual distribuição da receita tributária entre os níveis de governo é consequência das negociações políticas que resultaram na Constituição de 1988. No federalismo fiscal brasileiro, ao invés de um sistema de transferências intergovernamentais de recursos que proporcionasse a equalização fiscal, houve muito mais uma descentralização de receitas não acompanhada de uma descentralização concomitante de encargos e recursos. Houve, portanto, um problema central localizado na desarmonia entre a disponibilidade de recursos e a natureza das demandas que precisavam ser satisfeitas, isto é, os recursos obtidos pelos entes subnacionais não são suficientes, na maioria das vezes, para arcar com os encargos que lhes foram atribuídos. Por este motivo observa-se na escala municipal a necessidade, cada vez maior, de se buscar recursos através da celebração de convênios com as outras esferas federativas - principalmente com o governo federal. Ocorre que, pelo que se pode observar nos Mapas (Figuras 2 e 3), a liberação de recursos da União muitas vezes tende a atender aos interesses contidos nos PPAs específicos de cada presidente, ou seja, se o Plano Plurianual do presidente Luiz Inácio Lula da Silva previa, por exemplo, a implementação do processo de reforma urbana, a liberação de recursos para obras de infraestrutura nas cidades se efetivou para um maior número de municípios. 
Ademais, há que se apontar que o fato de a União também celebrar convênios com municípios que já possuem forte dinamismo econômico (podemos citar aqueles da Região Concentrada), visando impulsionar tais espaços a se inserirem na economia globalizada - tal ação, pode-se propor, reafirma os espaços luminosos do território (SANTOS e SILVEIRA, 2001). Há aqui uma contradição, pois se espera que o governo federal contrabalance, com sua forte presença, a relativa ausência de investimentos privados nos espaços opacos, e não que ajude a concentrar densidades onde a lógica do mercado já é intensa.

\section{AGRADECIMENTOS}

$\mathrm{O}$ artigo resulta de pesquisa realizada com apoio do CNPq - Conselho Nacional de Desenvolvimento Científico e Tecnológico, Brasil, através de concessão de Bolsa de Doutorado.

\section{REFERÊNCIAS}

ALMEIDA, Maria Hermínia Tavares de. Recentralizando a federação? Revista de Sociologia Política. Curitiba, n. 24, jun. 2005, pp. 29-40. Disponível em $<$ http://www.scielo.br/pdf/rsocp/n24/a04n24.pdf> acesso em 19 de março de 2009.

ARRETCHE, Marta. Quem taxa e quem gasta: a barganha federativa na federação brasileira. Revista de Sociologia e Política. Curitiba, n. 24, jun. 2005. Disponível em <http://www.scielo.br/pdf/rsocp/n24/ a06n24.pdf $>$ acesso em 05 de fevereiro de 2009.

BRASIL. Constituição, 1988. Constituição da República Federativa do Brasil. Texto constitucional de 1988. 28 ed. Brasília: Câmara dos Deputados, Coordenação de Publicações, 2007.

BRASIL. Ministério do Planejamento. Plano Plurianual 2004-2007. Mensagem ao Congresso Nacional. Brasília: MPOG, 2004.
BRASIL. Controladoria-Geral da União (CGU). Gestão de Recursos Federais. Manual para os agentes municipais. Brasília-DF: Secretaria de Controle Interno, 2005. Disponível em $<$ http://www.cgu.gov. br/Publicacoes/ManualGestaoRecursosFederais/Arquivos/CartilhaGestaoRecursosFederais.pdf $>$ acesso em 13 de janeiro de 2010.

BRASIL. Controladoria-Geral da União (CGU). (Sítio na internet). Diponível em: < http://www.cgu. gov.br/> vários acessos, 2013.

BRASIL. Calculadora do Cidadão. Banco Central do Brasil. Disponível em: <https://www3.bcb.gov.br/ CALCIDADAO/publico/exibirFormCorrecaoValores. do?method $=$ exibirFormCorrecaoValores $>$ acesso em 01 de agosto de 2013.

BRASIL. Portal da Transparência do governo federal do Brasil. (sítio na internet). Disponível em: $<$ http:// transparencia.gov.br/> vários acessos, 2013.

BRASIL. Presidência da República / Casa Civil. (Sítio na internet). Disponível em: $<\mathrm{http} / / \mathrm{www} 4$. planalto.gov.br/legislacao $>$ acesso em 12 de dezembro de 2011.

GALLO, Fabricio. Uso do território e federalismo como evento: a difusão regional de infraestruturas analisadas a partir das Transferências Intergovernamentais Voluntárias entre União e municípios. Tese (Doutorado em Geografia - Área de Análise Ambiental e Dinâmica Territorial). Instituto de Geociências. Universidade Estadual de Campinas, Campinas/SP, 2011.

GOTTMANN, Jean. A evolução do conceito de território. Boletim Campineiro de Geografia, Campinas, v. 2, n. 3, 2012 [1975].

LESSA, Antônio Carlos et al. Política externa planejada: os planos plurianuais e a ação internacional do Brasil, de Cardoso a Lula (1995-2008). Revista Brasileira de Política Internacional [on line]. Brasília, Vol 52, n. 1, 2009, p. 89-109. Disponível em <http:// www.scielo.br/pdf/rbpi/v52n1/v52n1a05.pdf $>$ acesso em 24 de maio de 2010. 
OLIVEIRA, Fabrício Augusto de. Crise, reforma e desordem do sistema tributário nacional. Campinas/ SP: Editora da UNICAMP, 1995.

SANGUIN, André-Louis. La géographie politique. Paris: Presses Universitaires de France, 1977.

SANTOS, Ângela Moulin Simões Penalva. O Município como Agente das Políticas Públicas: A Perspectiva das Cidades Médias. In: IX ENCONTRO NACIONAL DE ECONOMIA POLÍTICA, Uberlândia/MG, 2004. Anais..., Uberlândia, 2004.

SANTOS, Milton. O retorno do território. In SANTOS, Milton. Da totalidade ao lugar. São Paulo: EDUSP, 2005. A natureza do espaço. Técnica e tempo, razão e emoção. São Paulo: EDUSP, 2002. citec, 1993.

A urbanização brasileira. São Paulo: $\mathrm{Hu}-$

SANTOS, Milton et al. O papel ativo da geografia: um manifesto. Revista Território. Rio de Janeiro, ano V, n. 9, jul./dez. 2000.

SANTOS, Milton; RIBEIRO, Ana Clara Torres. $O$ conceito de Região Concentrada. Rio de Janeiro: IPPUR/UFRJ, (mimeo), 1979.

SANTOS, Milton; SILVEIRA, María Laura. O Brasil: território e sociedade no início do século XXI. São Paulo: Record, 2001.

SILVEIRA, María Laura. Globalización y territorio usado: imperativos y solidaridades. Cuadernos del Cendes, n. 69, 2008, p.1-19. 